\title{
Personal Identification using Cheiloscopy in South India
}

\section{Peter Kiran A*, Swetha Murthy Sharma, Dakshinamurthy Sridevi, Almeida Myfanwy Alonza and Mahemaa R}

Forensic Science, School of Graduate Studies, Jain University, Bangalore 560027, Karnataka, India

*Corresponding author: Peter Kiran A, Forensic Science, School of Graduate Studies, Jain University, J.C.Road, Bangalore 560027, Karnataka, India; Tel: +91897143588; E-mail: peterkiran.a@gmail.com

Received date: June 24, 2016, Accepted date: July 15, 2016, Published date: August 09, 2016

Copyright: (C) 2016 Kiran PA, et al. This is an open-access article distributed under the terms of the Creative Commons Attribution License, which permits unrestricted use, distribution, and reproduction in any medium, provided the original author and source are credited.

\begin{abstract}
Lip prints are an important form of transfer evidence, establishing the connection between a person and the crime scene and with the parallel increase in the sophistication in crime it is necessary to apply less known techniques like Cheiloscopy. The aim of this study is to find out the most and least common lip print pattern in males and females residing in South India and to study the extent of similarity among lip print patterns of twins and siblings residing in South India. The study was conducted on 50 pairs of twins and 50 pairs of siblings out of which 90 were males and 110 were females. The samples were collected using two methods - lipstick method and black powder development method. The most common lip print pattern was found to be Type II- Branched Pattern in both males (42.2\%) and females (43.63\%) and the least common pattern was found to be Type III- Intersected Pattern in both males (5.55\%) and females $(2.72 \%)$ in the South Indian Region. There was no correlation between the extent of similarity of lip print patterns among twins and siblings in the South Indian region.
\end{abstract}

Keywords: Cheiloscopy; Personal identification; Transfer evidence; Twins; Siblings

\section{Introduction}

Cheiloscopy is the study of the prints formed by the grooves or furrows present on the red part or the vermilion border of the human lips [1]. The pattern of lip print is unique to an individual [2] and thus can be used to fix the identity of a person [3]. Individual elements of vermilion zone patterns also contribute to the uniqueness of lip prints and thus help in individual identification.

Variations in patterns among males and females could help in sex determination [4]. The patterns recover after undergoing alterations like trauma, inflammation and diseases like herpes and they do not vary with environmental factors [5]. Age and smoking of cigarettes also do not change the lip print pattern.

However, there can be minor changes in the lip print pattern due to some cuts, surgical marks, and genetic deformations or due to a person's occupation like blowing musical instruments [6].

In a crime scene investigation, lip prints can be used to verify the presence of a person at the scene of crime and the analysis of the lip prints left at the scene of crime and their comparison with those of suspected person may be useful for identification [7].

Collection and preservation of lip print patterns include photographing the suspect's lips directly as well as applying lipstick, lip rouge, or other suitable transfer mediums to the lips and then having the individual press his or her lips to a piece of paper or cellophane tape or similar surface and then preserving the print by pasting on a bond sheet.

Latent prints can be taken against a suitable surface and then processing these prints with either conventional finger print developing powder or with a magna brush and magnetic powder. It can also be developed by using chemical and optical methods [8]. The developed prints should be lifted using fingerprinting tape and preserved on a bond sheet.

Some of the important contributors to Cheiloscopy include Fischer (1902) who was the first anthropologist to describe the furrows on the red part of the human lips, Locard (1932) who recommended the use of lip prints in personal identification and criminalization, Synder (1950) who reported in his book Homicide Investigation that the characteristics of the lips formed by lip grooves are as individually distinctive as finger prints and Kasprzak (1990) who conducted research to elaborate the practical use of lip prints.

Santos (1960) proposed that these lip characteristics could be used in personal identification and devised a simple system for classifying lip prints.

Suzuki and Tsuchihashi (1970) devised a classification which is widely used and is as follows:

1. Type I - A clear-cut groove running vertically across the lip (Figure 1)

2. Type I' - Partial-length groove of Type I (Figure 2)

3. Type II - A branched groove (Figure 3)

4. Type III - An intersected groove (Figure 4)

5. Type IV - A reticular pattern (Figure 5)

6. Type V - Other patterns (Figure 6)

Parents of individuals with cleft lip and/or palate are known to have a particular lip print pattern in which the grooves form circles. This lip print pattern is termed as type 'O' or 'whorl' pattern [9]. 
Citation: Kiran PA, Sharma SM, Sridevi D, Alonza AM, Mahemaa R (2016) Personal Identification using Cheiloscopy in South India. J Forensic

Page 2 of 4

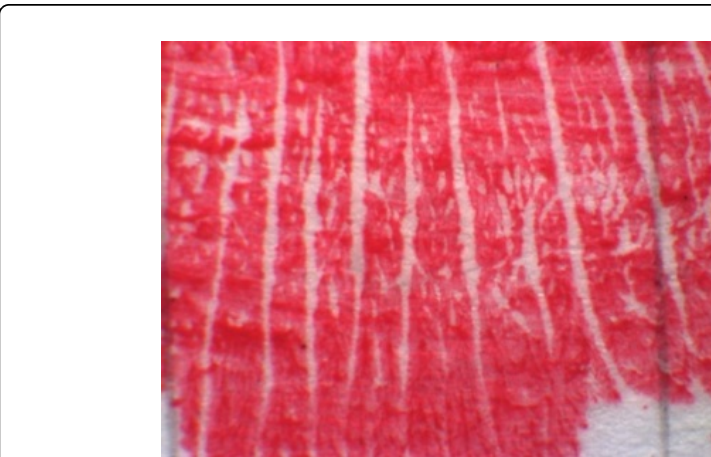

Figure 1: Type I- Fully vertical.

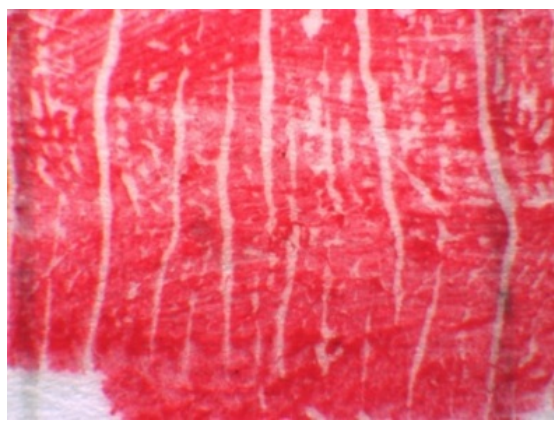

Figure 2: Type I’- Partially vertical pattern.

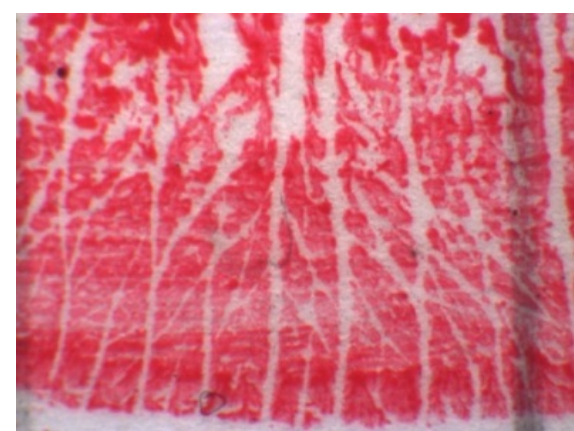

Figure 3: Type II- Branched pattern.

Latent prints were developed on glass surface using fingerprint black powder and was compared with standard lipstick prints to determine the effectiveness of the technique.

The percentage matching with self-lipstick print of good latent prints range from $25 \%$ to $100 \%$ [10]. The most predominant type of lip print among the Marathi community is found to be Type III- branched grooves. Lip prints are unique to an individual except in monozygotic twins [11].

Comparison of the lip print patterns among twins revealed that they were not absolutely identical and hence proved that their absolute dissimilarity [12]. Lip patterns in families with twins, had no significant correlation but some correlation was found in families with siblings.
Families with twin children showed no correlation between any particular lip patterns with blood groups however, in families with siblings, some correlation was observed [13]. Lip prints are hereditary yet considered to be individualistic, each possessing their own unique characteristics [14].

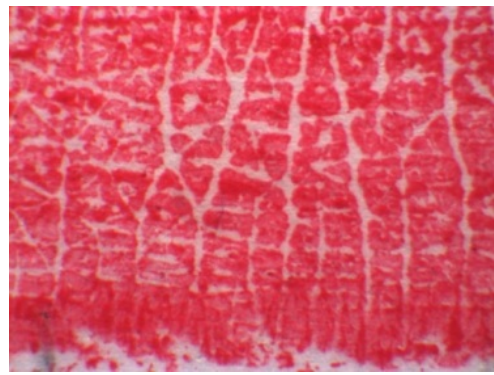

Figure 4: Type III- Intersected pattern.

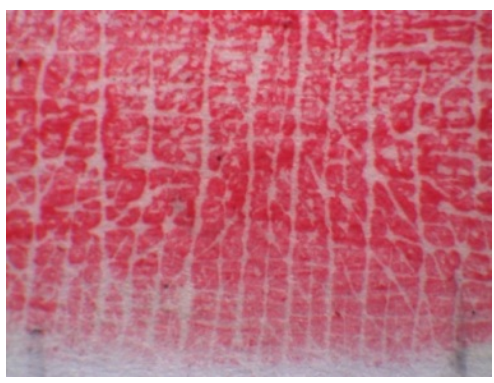

Figure 5: Type IV- Reticulate pattern.

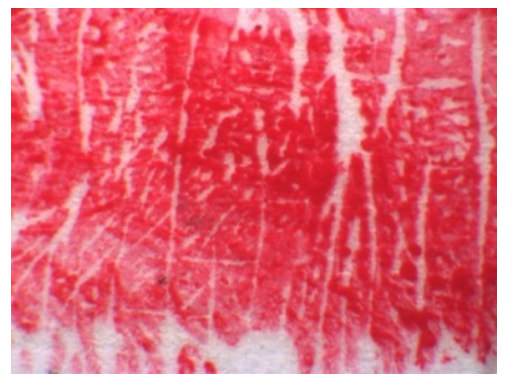

Figure 6: Type V- Other pattern.

\section{Methodology}

The study was conducted in Bangalore and Konini, Kerala belonging to the South Indian region on a population with age group within 2-39 years [15]. To find out the most and least common lip print pattern in the given population 90 males and 110 females were considered.

The method used to collect data was snowball technique. To study the extent of similarity of the lip print pattern among twins and siblings 50 pairs of twins and 50 pairs of siblings were considered [16].

Consent of all the individuals was obtained for the study. Individuals whose lips were free of any pathology, lesions or 
Page 3 of 4

deformities were considered for the study. The lips of the individuals were cleaned and red colored lipstick was applied on the lower lips with an applicator.

Then the glued portion of cellophane tape strip was placed on the subject's lips and the subject was asked to make a lip impression in the normal rest position of the lips by dabbing it in the center first and then pressing it uniformly toward the corners of the lips [17].

The cellophane strip was then stuck to the white chart paper for permanent record purpose. The second lip impression was taken on a clean dry glass slide which was developed using black powder and lifted with the lifting tape and was then stuck to the white chart paper for permanent record purpose. The center one centimeter of the lower lip, of each lip print sample was taken into consideration for analysis.

A magnifying glass and a stereo microscope were used to analyze the prints. The observations were recorded and the skewness values for the respective observations were calculated and represented in the graphical form.

\section{Discussion}

The most common lip print pattern among the males was found to be Type II- Branched Pattern (42.2\%). The least common was found to be Type III- Intersected Pattern (5.55\%). The most common lip print pattern among the females was found to be Type II- Branched Pattern (43.63\%) (Figures 7 and 8). The least common was found to be Type III- Intersected Pattern (2.72\%). The respective skewness values are 1.373855 and 0.732951 (Table 1). This results contradicts the earlier studies conducted in the same region.

\begin{tabular}{|c|c|c|c|}
\hline \multicolumn{2}{|l|}{ Males } & \multicolumn{2}{|l|}{ Females } \\
\hline Pattern & Frequency & Pattern & Frequency \\
\hline 1 & 12 & 1 & 25 \\
\hline l' & 7 & I' & 7 \\
\hline II & 38 & II & 48 \\
\hline III & 5 & III & 3 \\
\hline IV & 23 & IV & 22 \\
\hline V & 5 & $\mathrm{v}$ & 5 \\
\hline Mean & 15 & Mean & 18.33333 \\
\hline Median & 9.5 & Median & 14.5 \\
\hline Standard Deviation & 12.01 & Standard Deviation & 15.69 \\
\hline Skewness & 1.373855 & Skewness & 0.732951 \\
\hline
\end{tabular}

Table 1: Lip print pattern among males and females.

The percentage of similarity of lip print patterns in siblings was found to be $34 \%$ and that among twins was also found to be $34 \%$. The respective skewness values are 1.253482 and 1.380368 (Table 2). These percentages and skewness values being very close indicate that there is no correlation between the lip print patterns of twins when compared with siblings (Figures 9 and 10).

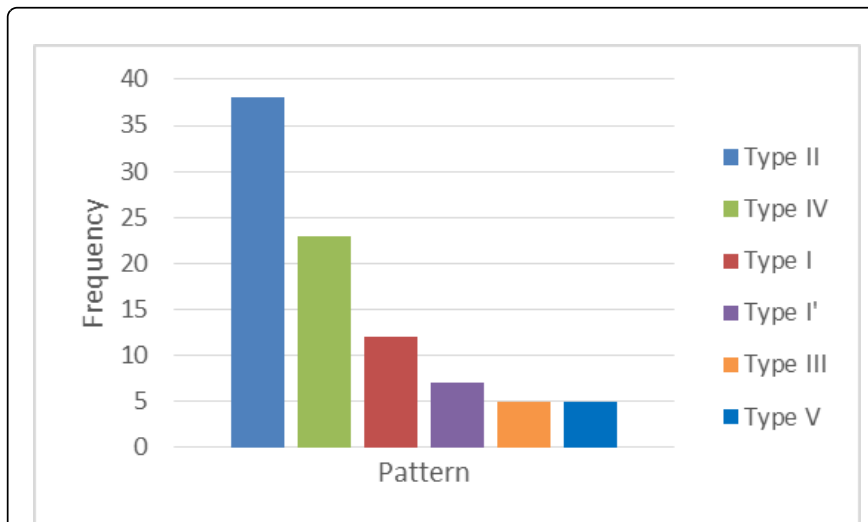

Figure 7: Lip print pattern among males.

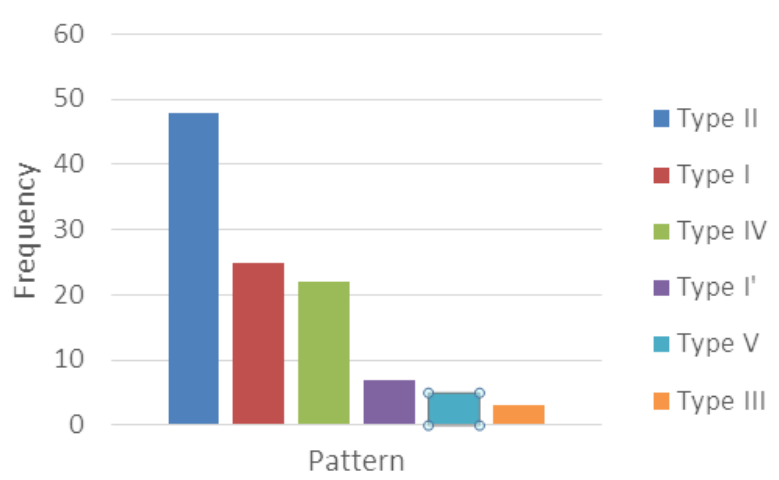

Figure 8: Lip print pattern among females.

\begin{tabular}{|l|l|l|l|}
\hline \multicolumn{2}{|l|}{ Siblings } & Twins \\
\hline $\begin{array}{l}\text { Pattern } \\
\text { Combination }\end{array}$ & Frequency & Pattern Combination & Frequency \\
\hline I-II & 0 & IV-IV & 0 \\
\hline I-VI & 0 & V-V & 0 \\
\hline II-V & 0 & I-IV & 0 \\
\hline II-VI & 0 & II-V & 0 \\
\hline III-VI & 0 & II-VI & 0 \\
\hline V-VI & 0 & III-IV & 0 \\
\hline I-I & 1 & IV-VI & 0 \\
\hline II-II & 1 & II-II & 1 \\
\hline IV-IV & 1 & I-II & 1 \\
\hline I-IV & 1 & IV-V & 1 \\
\hline IV-VI & 1 & V-VI & 1 \\
\hline I-V & 2 & II-III & 2 \\
\hline II-III & 2 & II-IV & 2 \\
\hline
\end{tabular}


Page 4 of 4

\begin{tabular}{|l|l|l|l|}
\hline III-IV & 2 & III-V & 3 \\
\hline IIIIV & 3 & III & 4 \\
\hline IV-V & 3 & I-V & 4 \\
\hline IIIII & 4 & I-VI & 4 \\
\hline V-V & 5 & III-VI & 5 \\
\hline III-III & 9 & I-III & 10 \\
\hline III-V & 15 & III-III & 12 \\
\hline Mean & 2.5 & Mean & 2.5 \\
\hline Median & 1 & Median & 1 \\
\hline $\begin{array}{l}\text { Standard } \\
\text { Deviation }\end{array}$ & 3.59 & Standard Deviation & 3.26 \\
\hline Skewness & 1.253482 & Skewness & 1.380368 \\
\hline
\end{tabular}

Table 2: Lip print pattern among siblings and twins.

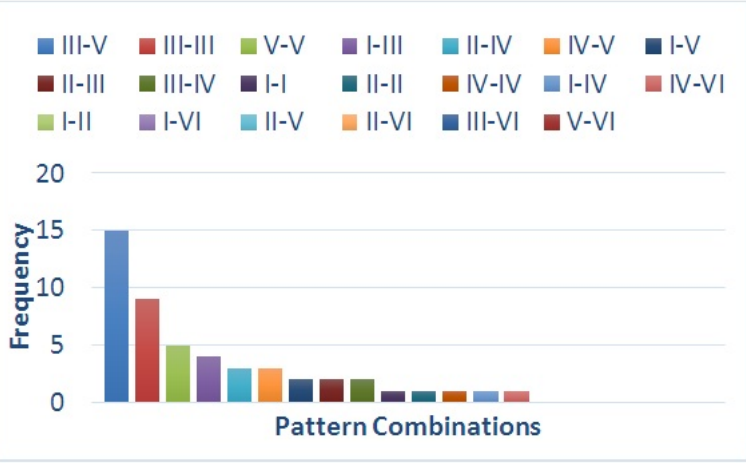

Figure 9: Lip print pattern among siblings.

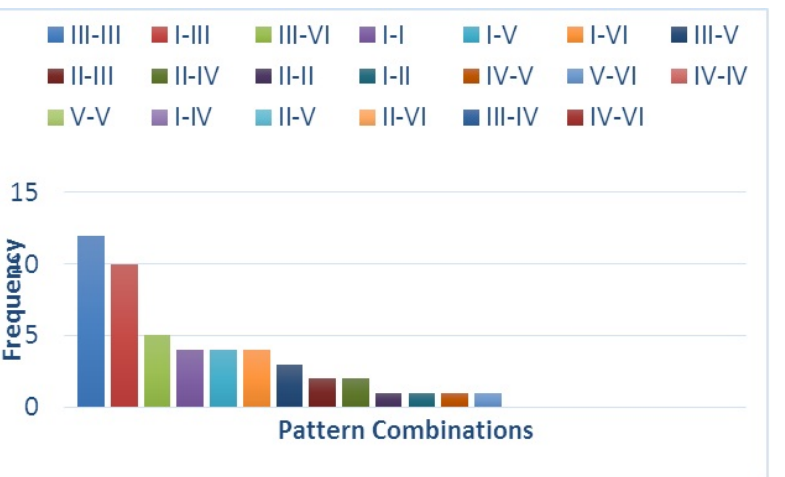

Figure 10: Lip print pattern among twins.

\section{Conclusion}

1. The most common lip print pattern in males and females is Type II (Branched). The least common lip print pattern in males and females is Type III (Intersected) in South Indian region.

2. There was no correlation between the extent of similarity of lip print patterns among twins and siblings in the South Indian region.

\section{References}

1. Saraswathi TR, Mishra G, Ranganathan K (2009) Study of lip prints. J Forensic Dent Sci 1: 28-31.

2. Verghese AJ, Somasekar M, UmeshBabu R (2010) The study on lip prints among the people of Kerala. J Indian Acad Forensic Med 32: 6-7.

3. Goonerathne I (2011) Establishing lip print analysis in Sri Lanka and its forensic use. Sri Lanka J Forensic Med Sci Law 1: 28-29.

4. Ghimire N, Nepal P, Upadhyay S, Subba A, Kharel B, et al. (2013) Lip print pattern: An Identification tool. Health Renaissance pp: 229-233.

5. Augustine J, Barpande SR, Tupkari JV (2008) Cheiloscopy as an adjunct to forensic identification: Study of 600 individuals. J Forensic Odontostomatol 26: 44-52.

6. Romanowska EJ (2014) Forensic cheiloscopy: Individual identification on the basis of lip prints.

7. Verghese AJ, Mestri SC (2011) A Study of Efficacy of Lip Prints as an Identification Tool among the People of Karnataka in India. J Indian Acad Forensic 33: 200-202.

8. Dineshshankar J, Ganapathi N, Yoithapprabhunath, Yoithapprabhunath TR, Maheswaran T, et al. (2013) Lip Prints: Role in Forensic Odontology. J Pharm Bioallied Sci 5: S95-S97.

9. Manasa Ravath CJ, Girish HC, Murgod S, Hegde RB, Savita JK (2014) Lip Prints and Inheritance of Cleft Lip and Cleft Palate. J Clin Diagn Res 8: ZC28-ZC32.

10. Dwivedi N, Agarwal A, Kashyap B, Raj V, Chandra S (2013) Latent lip print development and its role in suspect identification. J Forensic Dent Sci 5: 22-27.

11. Neeti Kapoor, Prakash Tiwari (2013) Study of Lip Prints among the Population of Marathi Community. IJSER 3: 1-8.

12. Jaishankar S, Jaishankar N, Shanmugam S (2010) Lip Prints in Personal Identification. JIADS 1: 23-26.

13. Patel S, IshPaul, Madhusudan AS, Ramesh G, Sowmya GV (2010) A study of lip prints in relation to gender, family and blood group. Int J Oral Maxillofac Pathol 1: 4-7.

14. Petersen LC (2009) Lip prints. Anil Aggrawal's Internet J Forensic Med Toxicol 10: 1-62.

15. Randhawa K, Narang RS, Arora PC (2011) Study of the effect of age changes on lip print pattern and its reliability in sex determination. J Forensic Odontostomatol 29: 45-51.

16. Dongarwar GR, Bhowate RR, Degwekar SS (2013) Cheiloscopy-Method of Person Identification and Sex Determination. Sci Rep 2: 612.

17. Bindal U, Jethani SL, MehrotraN, Rohatgi RK, Arora M, et al. (2009) Lip prints as a method of identification in human beings. J Anat Soc India 58: $152-155$. 